\title{
Aerosolisation in endonasal endoscopic pituitary surgery
}

\author{
Rana S. Dhillon ${ }^{1}$ - Lana V. Nguyen ${ }^{1} \cdot$ Wagih Abu Rowin $^{2} \cdot$ Ruhi S. Humphries ${ }^{3} \cdot K_{\text {Kevin }}$ Kevin $^{2}$ - Jason D. Ward ${ }^{3}$. \\ Andrew Yule ${ }^{4}$ Tuong D. Phan ${ }^{5,7} \cdot$ Yi Chen Zhao $^{6} \cdot$ David Wynne $^{1} \cdot$ Peter M. McNeill ${ }^{1}$. Nicholas Hutchins ${ }^{2}$. \\ David A. Scott ${ }^{5,7}$
}

Accepted: 4 January 2021 / Published online: 19 January 2021

(c) The Author(s), under exclusive licence to Springer Science+Business Media, LLC part of Springer Nature 2021

\begin{abstract}
Purpose To determine the particle size, concentration, airborne duration and spread during endoscopic endonasal pituitary surgery in actual patients in a theatre setting.

Methods This observational study recruited a convenience sample of three patients. Procedures were performed in a positive pressure operating room. Particle image velocimetry and spectrometry with air sampling were used for aerosol detection. Results Intubation and extubation generated small particles $(<5 \mu \mathrm{m})$ in mean concentrations 12 times greater than background noise $(\mathrm{p}<0.001)$. The mean particle concentrations during endonasal access were 4.5 times greater than background $(\mathrm{p}=0.01)$. Particles were typically large $(>75 \mu \mathrm{m})$, remained airborne for up to $10 \mathrm{~s}$ and travelled up to $1.1 \mathrm{~m}$. Use of a microdebrider generated mean aerosol concentrations 18 times above baseline $(p=0.005)$. High-speed drilling did not produce aerosols greater than baseline. Pituitary tumour resection generated mean aerosol concentrations less than background $(\mathrm{p}=0.18)$. Surgical drape removal generated small and large particles in mean concentrations 6.4 times greater than background $(\mathrm{p}<0.001)$.

Conclusion Intubation and extubation generate large amounts of small particles that remain suspended in air for long durations and disperse through theatre. Endonasal access and pituitary tumour resection generate smaller concentrations of larger particles which are airborne for shorter periods and travel shorter distances.
\end{abstract}

Keywords Aerosol-generating procedure $\cdot$ Aerosols $\cdot$ COVID-19 $\cdot$ Endonasal endoscopic pituitary surgery $\cdot$ Occupational exposure

Rana S. Dhillon

rana.dhillon@svha.org.au

1 Department of Neurosurgery, St Vincent's Hospital Melbourne, 41 Victoria Parade, Fitzroy, VIC 3065, Australia

2 Department of Mechanical Engineering, University of Melbourne, Grattan Street, Parkville, VIC 3010, Australia

3 Climate Science Centre, CSIRO Oceans and Atmosphere, 107 Station Street, Aspendale, VIC 3195, Australia

4 ARPANSA (Australian Radiation Protection and Nuclear Safety Agency), 619 Lower Plenty Road, Yallambie, VIC 3085, Australia

5 Department of Anaesthesia and Acute Pain Medicine, St Vincent's Hospital Melbourne, 41 Victoria Parade, Fitzroy, VIC 3065, Australia

6 Department of Ear, Nose and Throat Surgery, St Vincent's Hospital Melbourne, 41 Victoria Parade, Fitzroy, VIC 3065, Australia

7 University of Melbourne, Parkville, Australia

\section{Introduction}

In March 2020, infection of healthcare workers during an endonasal pituitary surgery in a patient with coronavirus disease (COVID-19) was reported in mainstream media and in rapid online publications [1-4]. Peak bodies in neurosurgery and otolaryngology recommended that all non-urgent endonasal surgery be suspended, believing that high speed drilling near the sinonasal mucosa aerosolised a high viral load in theatre [5]. In April 2020, Zhu and colleagues published the facts of the case which suggested that intra-operative transmission did not in fact occur [6]. Endonasal surgery has since recommenced with safeguards, but the concerns surrounding aerosolisation remain [7-11].

Cadaveric studies have provided useful data but these do not replicate the temperature, humidity and mucosal surface characteristics of live humans [12-15]. Furthermore, operating theatres undergo multiple air exchanges which affects 
how suspended particles behave [16, 17]. In this paper, we define 'aerosol' as particles suspended in air, 'small' particles as $\leq 5 \mu \mathrm{m}$ and 'large' particles as $>5 \mu \mathrm{m}$ [18]. This study aims to determine which stages of endonasal endoscopic pituitary surgery generate aerosols, and to characterise the aerosols produced.

\section{Methods}

\section{Study design and population}

We performed a prospective, single-centre observational study of three patients. Institutional Review Board approval was obtained in accordance with state and federal guidelines (Ref: LRR 099/20, ID: 64592). Informed consent was obtained from all participants. A convenience sample was taken from a waiting list of patients awaiting elective endonasal endoscopic pituitary surgery. Exclusion criteria were patients who were under the age of 18 , unable to consent, pregnant or demonstrating symptoms of COVID- 19 .

\section{Procedural conditions}

All procedures took place in an operating theatre of size $6 \times 7 \times 3 \mathrm{~m}$, of volume $126 \mathrm{~m}^{3}$, under $20 \mathrm{~Pa}$ of positive pressure relative to the setup area, at a temperature of $20^{\circ} \mathrm{C}$, and humidity of $48.2 \%$. Air entered the room at velocities of 0.97 to $1.04 \mathrm{~m} / \mathrm{s}$ via four ceiling air diffusers with HEPA $530 \mathrm{~mm}$ filters and was extracted via four wall air intakes. Air was exchanged at $65 \mathrm{~m}^{3}$ per minute equating to 26 room volume air exchanges per hour. All theatre entrants wore $n 95$ masks to prevent contamination with staff-generated aerosol. Patients were intubated on the operating table by a consultant anaesthetist. The endonasal approach to the pituitary fossa was performed endoscopically by a consultant otolaryngologist, and a consultant neurosurgeon performed pituitary tumour removal. The patient was then extubated on the operating table. Two non-invasive methods that involved no modifications to standard of care were used to detect aerosol: particle image velocimetry (PIV) to detect large particles and air sampling with spectrometry to detect small particles.

\section{Particle image velocimetry}

PIV involved illuminating a target area with a light sheet generated by a class IIIb $50 \mathrm{~mW} 532 \mathrm{~nm}$ wavelength green laser. The PIV target areas were immediately superior to the patient's nasal aperture, $300 \mathrm{~mm}$ caudal to the nasal aperture, and $1100 \mathrm{~mm}$ caudal to the nasal aperture. Clinical laser safety precautions were followed. Disturbances in the light sheet were captured with low- and high-speed cameras. The low-speed system was a Nikon D810 camera (Nikon
Australia, Pty Ltd) focussed on a field of view of $80 \times 20 \mathrm{~cm}$, running continuously at 60 frames per second with a digital resolution of $110 \mu \mathrm{m} / \mathrm{pixel}$. The high-speed system was a PCO dimax HS4 camera (PCO AG, Germany) focussed on a $15 \times 15 \mathrm{~cm}$ field of view, running at 1000 frames per second for 10 -s bursts with a digital resolution of $75 \mu \mathrm{m} /$ pixel.

\section{Air sampling}

An Aerodynamic Particle Sizer Spectrometer (APS model 3320, TSI Incorporated, Shoreview, Minnesota, USA) measured the time-of-flight of particles between two laser beams as they move within an accelerating sheath flow, resulting in aerosol counts binned by aerodynamic diameter. The size resolution was 32 bins per decade, spaced logarithmically. A Mini Wide Range Aerosol Spectrometer (MiniWRAS model 1371, GRIMM Aerosol Technik Ainring GmbH, Germany) measured continuously the size distribution of aerosol across the range 0.01 to $35 \mu \mathrm{m}$, The MiniWRAS used electrical mobility spectrometry to measure the mobility diameter of ultrafine particles between 0.01 and $0.2 \mu \mathrm{m}$ in diameter, and optical light scattering to measure particle diameters between 0.25 and $35 \mu \mathrm{m}$. The temporal sampling rate of the MiniWRAS was 1 sample per minute. The size resolution was lower than the APS, with 10 size bins between 0.01 and $0.193 \mu \mathrm{m}$.

Air was sampled at a rate of $5.3 \mathrm{~L} / \mathrm{min}$ through an inlet positioned $50 \mathrm{~mm}$ superior and distal to the patient's nasal aperture. The aerosol sample was transported to the two instruments via a $2500 \mathrm{~mm}$ long, $1.3 \mathrm{~cm}$ diameter conductive silicon tube. Other than transportation losses through the tube, the aerosol matrix was not altered. The opening of the inlet was positioned $500 \mathrm{~mm}$ superior and $500 \mathrm{~mm}$ caudal to the target area and represents the micro-environment surrounding the proceduralist's head.

\section{Calculating particle counts and trajectory using PIV}

High-intensity peaks in each image were used to calculate particle counts. An in-house particle tracking velocimetry algorithm detected particles with a specified intensity threshold in one frame, then searched for the pair of that particle in subsequent frames. For particles travelling faster than the recording rate of the low-speed imaging system, trajectory lines were produced and these were used to calculate the landing distance and time.

\section{Calculating detection limits}

Air sampling was performed in the empty operating theatre from 3:00 p.m. the previous day to 7:30 a.m. the morning of surgery. The detection limit for each instrument was calculated as the mean plus three standard deviations during 
this overnight clean period (counts $0.04 \mathrm{~cm}^{-3}$ and $60 \mathrm{~cm}^{-3}$ for APS and MiniWRAS, respectively). A similar process was also undertaken as described above, but in an occupied theatre in the absence of an active procedure, to establish the background noise created by normal theatre traffic (counts $0.09 \mathrm{~cm}^{-3}$ and $60 \mathrm{~cm}^{-3}$, respectively). Detection limits for PIV were established using low-speed images obtained in the same conditions.

\section{Statistical analysis}

Continuous variables were described using mean and median values. Independent samples t-test was used to assess for differences between groups and a value of $p<0.05$ was defined as significant. Analyses were performed using open source SciPy v1.5.2 (Scientific computing in Python). Values were expressed as multiples above baseline concentrations.

\section{Results}

\section{Intubation and extubation}

The mean particle concentrations observed on APS data during intubation and extubation were up to 12 times greater than baseline values $(\mathrm{p}<0.001)$. These mean particle concentrations were significantly greater than endonasal access $(\mathrm{p}<0.001)$ and pituitary tumour resection $(\mathrm{p}<0.001)$. Bag and mask ventilation during intubation produced spikes in particle concentration up to 300 times greater than background. The particle sizes observed during intubation were generally $<5 \mu \mathrm{m}$ (Fig. 1). During extubation, bag and mask ventilation, throat pack removal and patient coughing were associated with aerosol production of small particles $<4 \mu \mathrm{m}$ (Fig. 1).

\section{Endonasal access}

The mean particle concentrations on APS during endonasal access were up to 4.5 times greater than baseline value $(p=0.01)$. Turbinectomy and sphenoidotomy using a microdebrider was the only procedural step of endonasal access associated with a mean particle concentration above baseline (18 times greater, $\mathrm{p}=0.005$ ). Mostly large particles $>75 \mu \mathrm{m}$ were produced (Fig. 2). This was supported by PIV data. Three steps produced non-significant increases in mean particle concentration: use of a backbiting rongeur (up to 3 times baseline, $p=0.83$ ), use of a Kerrison rongeur (up to 3 times baseline, $p=0.53$ ) and monopolar diathermy (up to 4.7 times baseline, $p=0.20$ ). High speed drilling of the sphenoid keel, sphenoid septum or sella turcica floor; raising of a nasoseptal flap; and scissors did not produce mean aerosol greater than background values in either PIV or air sampling systems. Though not statistically significant, spikes in particle concentration were evident on APS measurements during manipulation of sphenoid mucosa using Blakesley
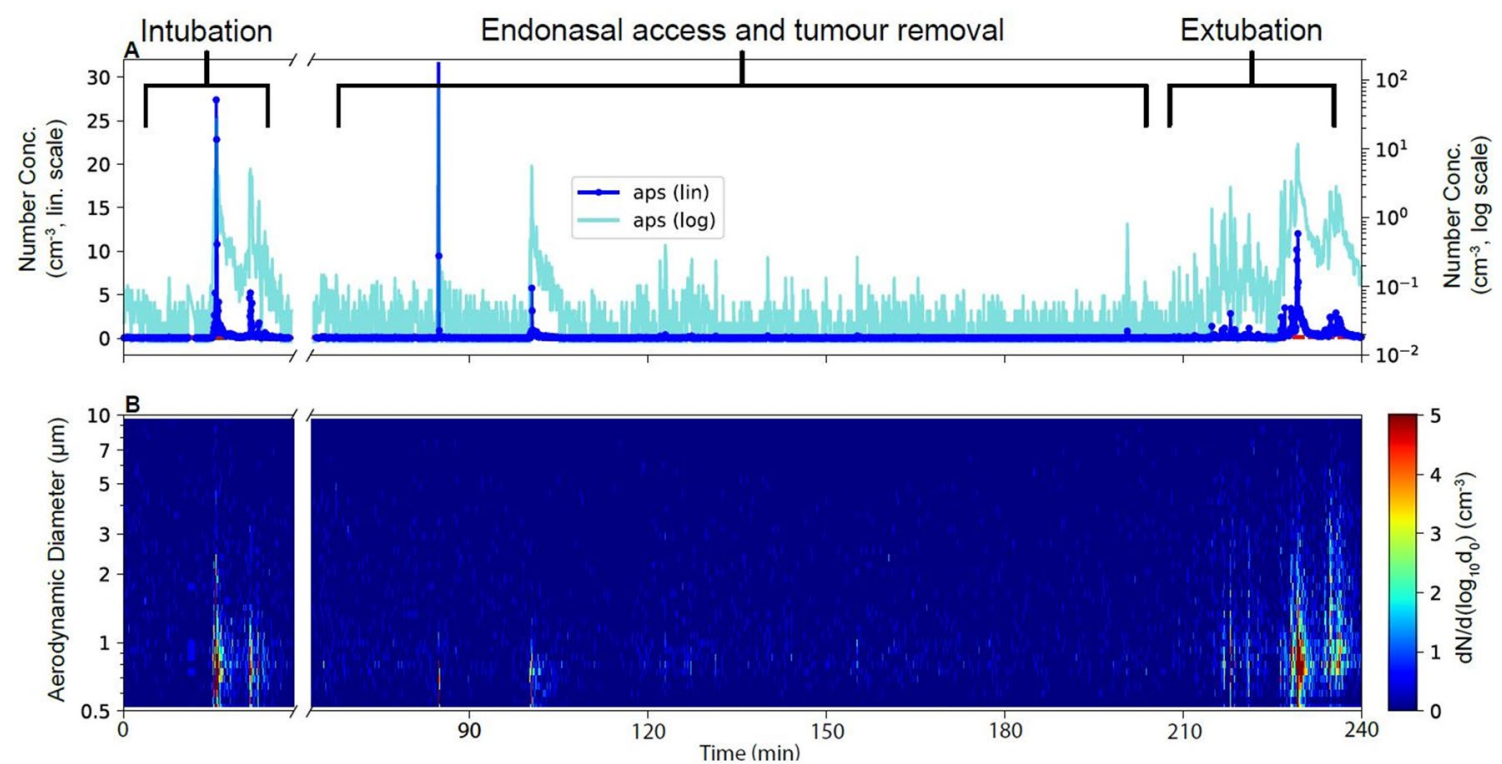

Fig. 1 Timeline series of particle concentrations and diameter measured by aerodynamic particle sizer (APS) during intubation, endonasal access, pituitary tumour removal and extubation. a Total particle number concentrations with linear and log scales shown in dark and light blue, respectively. Dashed lines represent the detection limit (mean +3 standard deviations) during an empty theatre (green) and during theatre setup (red). b Aerosol size distribution with colours showing the number concentration in each size bin. The integrated size distributions correspond to total concentrations 

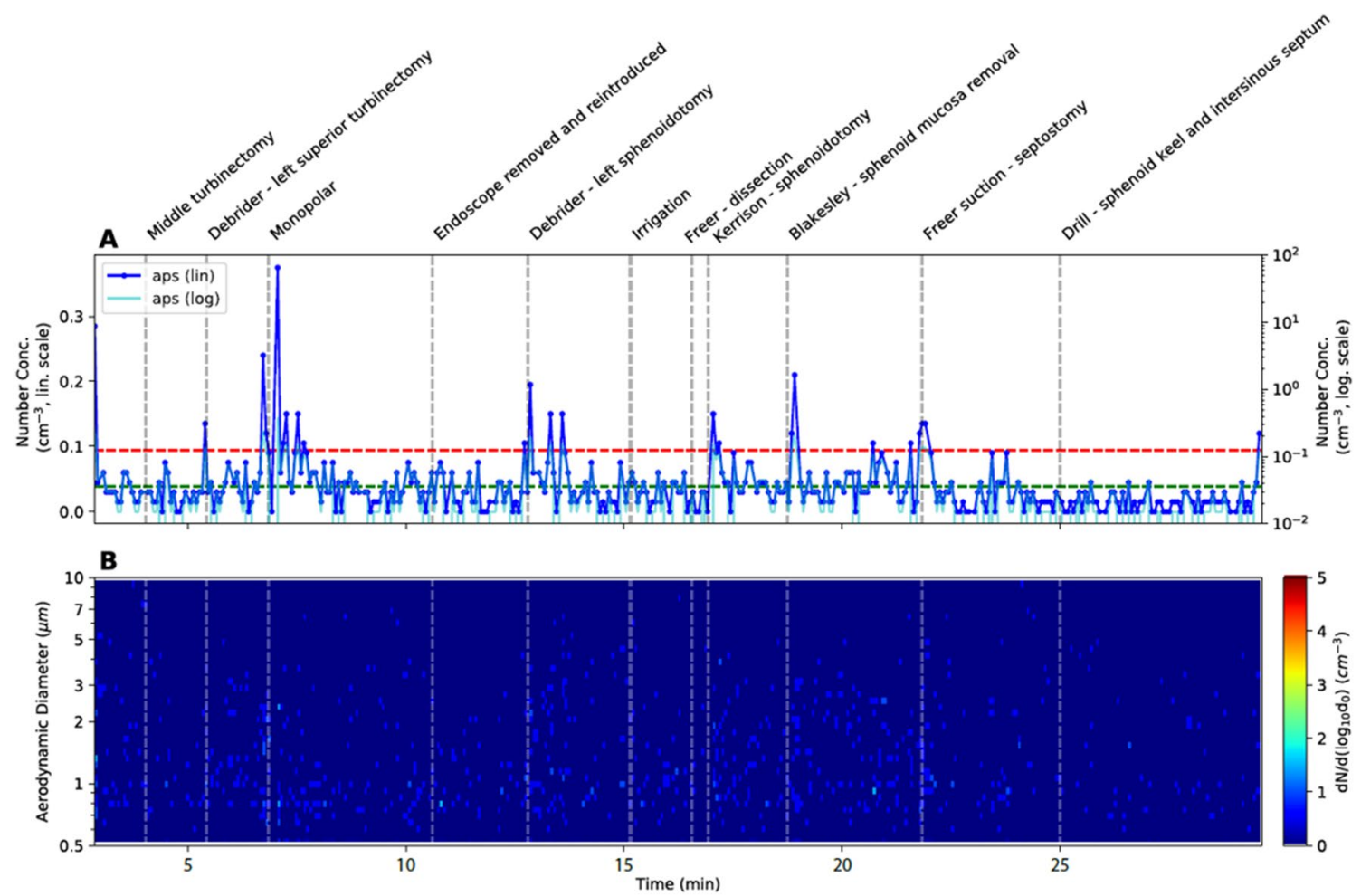

Fig. 2 Timeline series of particle concentrations and diameter measured by aerodynamic particle sizer during endonasal access. $\mathbf{a}, \mathbf{b}$ are as for Fig. 1

nasal forceps ( 7.9 times baseline, $\mathrm{p}=0.13)$, bulb irrigation of the nose (6.7 times baseline, $\mathrm{p}=0.40$ ) and use of a freer suction elevator to perform a pedicle sparing posterior septectomy (3.9 times baseline, $\mathrm{p}=0.66$ ) (Fig. 2).

\section{Pituitary tumour resection}

The mean particle concentrations measured by APS during pituitary tumour resection were less than baseline values but this difference was not significant $(\mathrm{p}=0.18)$. Use of a curved spatula, curettes, or suction within the sella were not associated with increases in aerosol above baseline in either air sampling (Fig. 3) or PIV measurements.

\section{Surgical drape removal}

The mean particle concentrations observed on APS data during drape removal were 6.4 times greater than background $(\mathrm{p}<0.001)$. Both small and large particles were produced ranging from 1 to $>5 \mu \mathrm{m}$ (Fig. 4 ).

\section{Dispersion medium}

The dispersion medium of particles was calculated from PIV data. The procedural step that generated the largest particle count was used for each procedure. For intubation and extubation, this was bag and mask ventilation. For endonasal access and pituitary tumour resection, that step was use of a microdebrider. Particles generated by intubation and extubation were relatively small, remaining suspended in airflows at $1100 \mathrm{~mm}$ from the patient's nose with a tendency to travel craniocaudally. Based on the observed trajectories, these particles were calculated to spread within the confines of theatre and to persist for at least $110 \mathrm{~s}$, a time determined by the rate of air exchange. Particles generated by endonasal access settled at a distance of $1.1 \mathrm{~m}$ from the nose and remained airborne for a duration of $10 \mathrm{~s}$. A summary of the landing distance and airborne duration of particles in each procedure is listed in Table 1 and shown schematically in Fig. 5.

\section{Discussion}

Our data demonstrate that intubation and extubation generate significantly greater mean concentrations of smaller particles compared to endonasal access and pituitary tumour resection (Fig. 1). Certain steps such as manipulation of endonasal mucosa with Blakesley forceps during endonasal access or bulb irrigation during pituitary tumour resection were associated with large spikes in particle number concentration compared to baseline as captured in Figs. 2 and 3. 


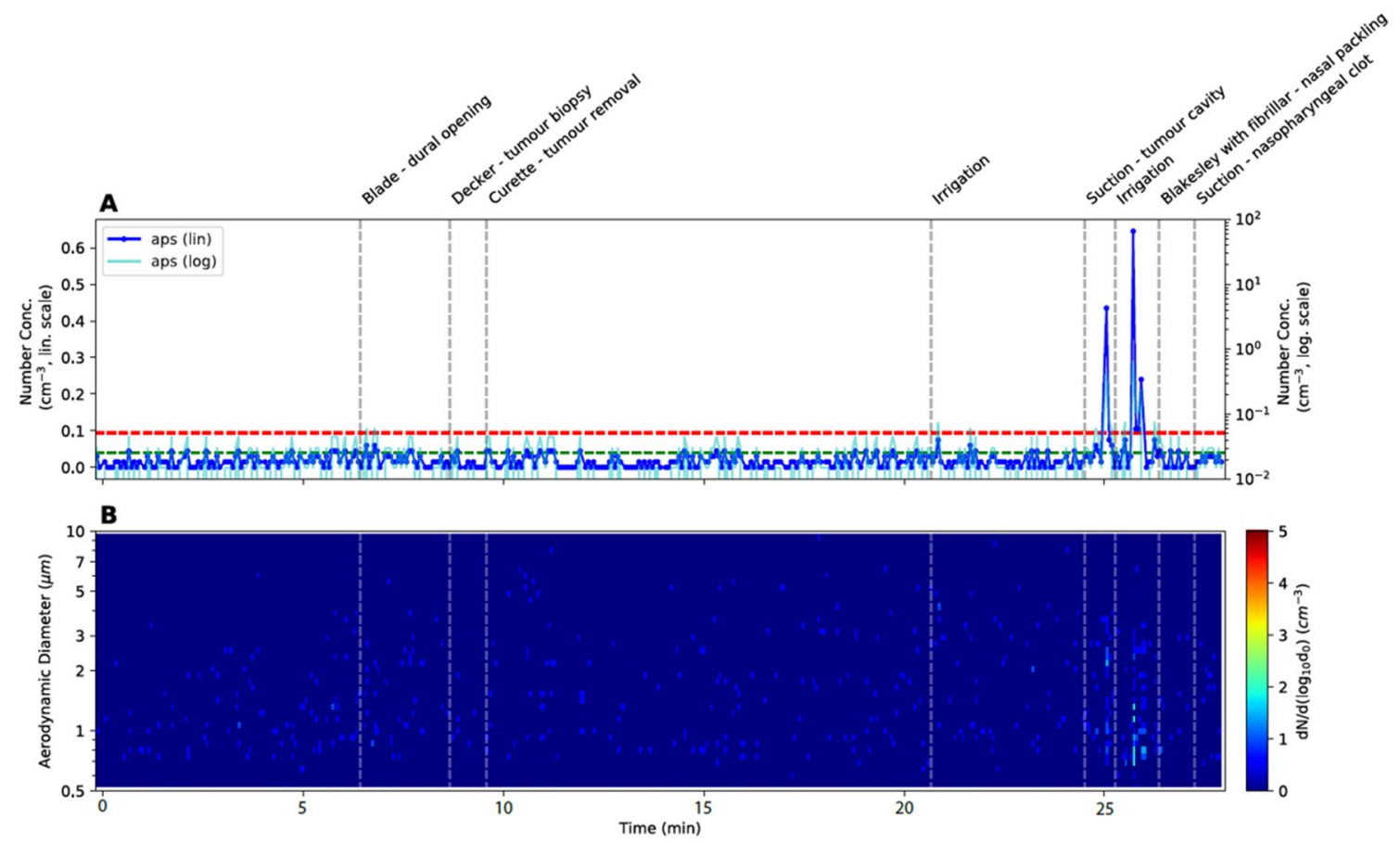

Fig. 3 Timeline series of particle concentrations and diameters measured by aerodynamic particle sizer during tumour resection. $\mathbf{a}, \mathbf{b}$ are as for Fig. 1
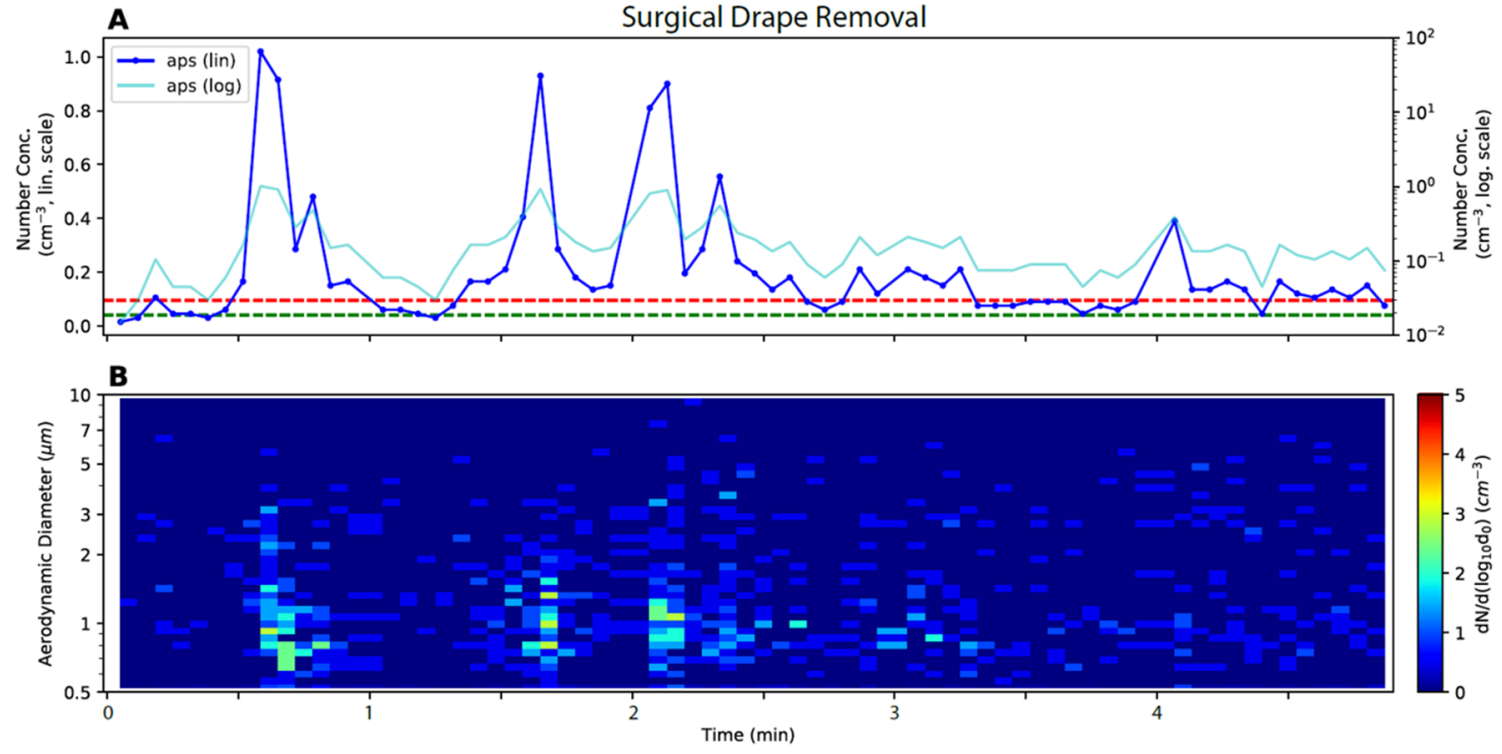

Fig. 4 Timeline series of particle concentrations and diameters measured by aerodynamic particle sizer during drape removal. a, $\mathbf{b}$ are as for Fig. 1

However these steps did not produce statistically significant mean particle concentrations above baseline.

The likely cause of this mismatch is the variable frequency of spikes in peak particle concentration. As our statistical test considered mean concentrations, a procedural step containing infrequent spikes in particle concentration but overall low particle counts may be deemed statistically insignificant. However these peak particle concentrations may be clinically significant to healthcare workers' aerosol exposure risk.

It is useful to dichotomise particles as either small $(\leq 5 \mu \mathrm{m})$ or large $(>5 \mu \mathrm{m})$ to understand their dispersion 
Table 1 Particle landing distance and time in different procedures

\begin{tabular}{lll}
\hline Procedure & $\begin{array}{l}\text { Landing radius of parti- } \\
\text { cles generated }(\mathrm{m})\end{array}$ & $\begin{array}{l}\text { Airborne duration } \\
\text { of particles gener- } \\
\text { ated (s) }\end{array}$ \\
\hline Intubation & Suspended in air & $>138$ \\
Endonasal access & 1.1 & $\sim 10$ \\
Extubation & Suspended in air & $>110$ \\
\hline
\end{tabular}

characteristics [18]. Small particles remain suspended in air flows resulting in long airborne durations and the tendency to travel farther [19]. Large particles behave ballistically resulting in shorter airborne durations and the tendency to settle on surfaces that are close to the source [20]. Relative humidity is also an important consideration and recent modelling suggests that moist micro-environments around small particles may lead to greater airborne durations [21].
The change in behaviour with particle size can inform 'safe distances' and 'safe times' to protect healthcare workers in operating theatres. Particles were observed to travel from the patient's nose in a caudal direction. It is unclear whether this is because only caudally travelling particles are released through the nasal aperture, or because of prevailing air currents in the operating theatre. This suggests that as a general principle, areas close to the procedural aperture and areas towards the patient's feet are best avoided.

The current literature on whether key steps of endonasal surgery should be considered aerosol-generating procedures is based on pre-clinical modelling. Workman and colleagues have performed two cadaveric studies to assess aerosol generation during drilling and microdebridement, the first using fluorescein and visual inspection, the second using an optical particle sizer $[13,14]$. Both of these studies found that drilling generated aerosol. Subsequently, Dharmarajan and colleagues utilised a cascade impactor

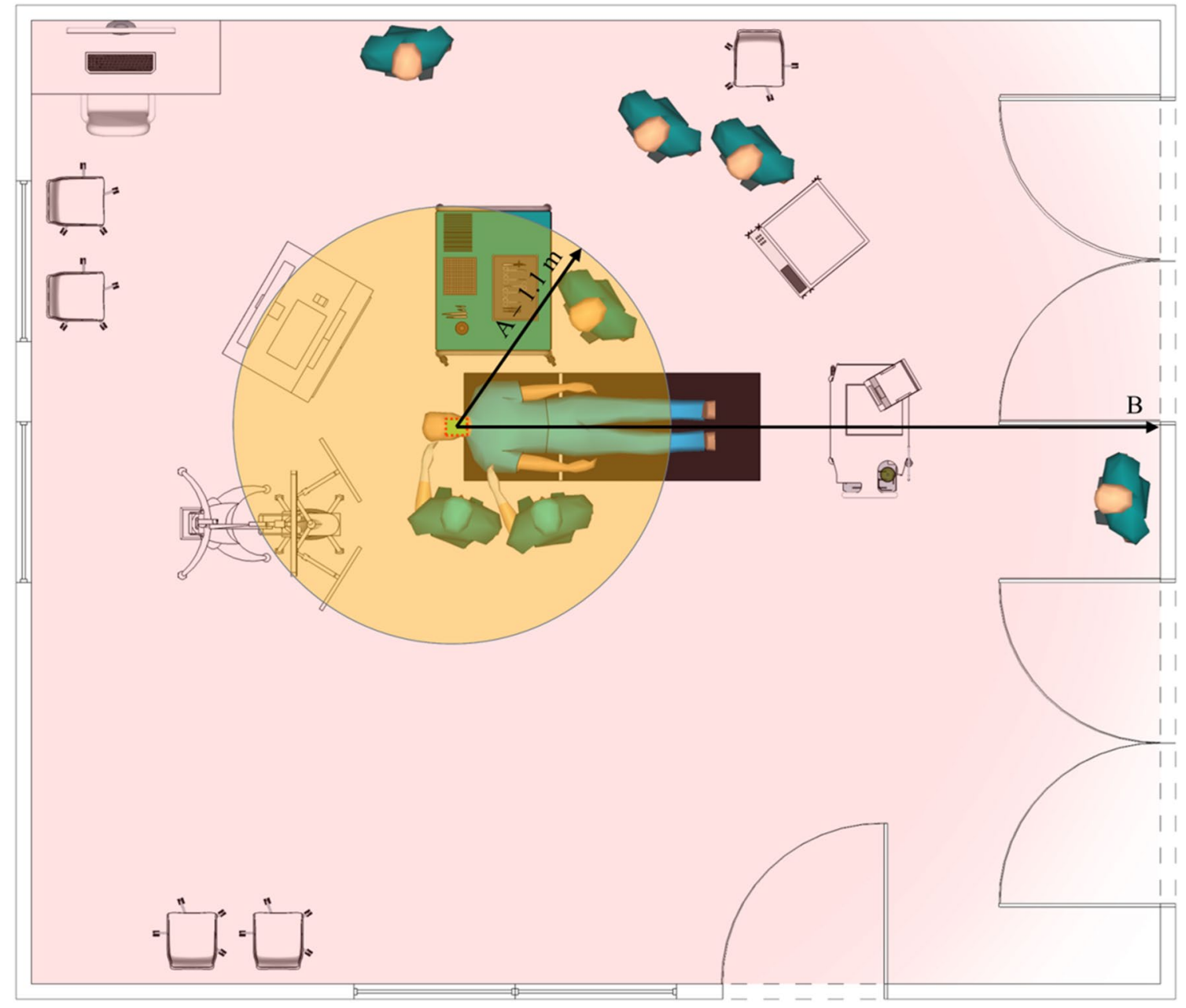

Fig. 5 Schematic diagram showing the distance travelled by particles generated during steps of endonasal surgery. Distance A represents use of a microdebrider during endonasal access. Distance B repre- sents bag mask ventilation in a paralysed patient during intubation and extubation, with distance limited by the confines of the theatre 
to demonstrate the aerosol produced during endonasal drilling of cadaver and manikin models can be completely mitigated with placement of a suction instrument in the nasal cavity or nasal pharynx [15].

In contrast to these studies, we found high-speed drilling of bone did not generate more aerosol than background noise, regardless of whether suction was used. This was an unexpected finding; those familiar with endoscopic pituitary surgery are also familiar with the white plume that obscures vision during drilling which is often thought to represent aerosol. One possible explanation is that drilling produces large particles which settle quickly within the nose and do not contribute to the plume of smaller particles outside the nose. Pre-clinical models do not replicate the humidity or mucosal characteristics of live humans [22]. These variables affect the characteristics of the aerosol produced [23]. Furthermore, these previous studies do not replicate the environmental conditions unique to operating theatres in terms of staff movement, currents, air exchange and atmospheric pressures. These variables affect the flow in which the aerosol resides [16, 17].

Our results also demonstrate that the methods used were sufficiently sensitive to avoid false negatives. Firstly, particle sizes down to $0.01 \mu \mathrm{m}$ were detectable. Secondly, very low concentrations of particles were detectable. This was shown by the fact that background noise quantifications were consistent with background counts performed as part of operating theatre accreditation which were measured over much longer time periods.

We recommend that during endonasal access, healthcare workers not directly involved in the operation maintain a distance of at least $1.1 \mathrm{~m}$ from the patient's nose and avoid the region caudal to the patient's nose (Fig. 5). Endonasal access produced mostly large particles but some small particles were observed too. Therefore, personal protective equipment (PPE) needs to protect against both large and small particles which includes tight fitting eye protection and $\mathrm{n} 95$ masks to prevent plumes of small particles entering gaps between PPE and the wearer's face. We also recommend that surgical drape removal be treated as an aerosol-generating procedure. This is often done without great care, but our findings suggest that particles have likely settled on the drapes during the procedure and their removal stirs up a plume.

Limitations of this study include a small sample size and a lack of assessment of the biological activity of the aerosols generated. However, there is data to suggest that the virus remains biologically active when aerosolised in a similar manner [24, 25]. Lastly, PIV requires a clean line of sight for the laser light sheet which at times was obscured by the proceduralist's hands and the APS and miniWRAS are point measurement techniques which can underestimate a threedimensional plume.

\section{Conclusion}

This study provides data on aerosol generation from actual patients in an operating theatre setting. It demonstrates that endonasal endoscopic pituitary surgery is not as high risk as previously thought. Intubation and extubation generate large concentrations of small particles, that remain suspended in air and spread throughout theatre. Endonasal access and pituitary tumour resection on the other hand generate smaller concentrations of larger particles which are airborne for shorter periods and travel shorter distances. Importantly, there are key steps that are particularly aerosol generating such as bag and mask ventilation during intubation and use of a microdebrider during endonasal access. PPE choice should protect against both small and large particles, and surgical drape removal should be treated as an aerosol-generating procedure.

Author contributions RSD conceived the study. RSD, DAS and PMN designed the study and prepared the ethics submission. RSD, TP and YCZ performed the invasive procedures. WAR, KK, RH, JW, DW and LN collected data. WAR, KK, NH, RH, JW and AY analysed the data. RSD, DAS, WAR, KK, NH and RH interpreted the data. WAR and RH prepared the figures. RSD, LN, DAS, WAR, RH and DW wrote the manuscript. All authors critically revised the manuscript and approved the final version.

Funding There was no funding source for this study.

Data availability The datasets generated during and/or analysed during the current study are available from the corresponding author on reasonable request.

\section{Compliance with ethical standards}

Conflict of interest $\mathrm{NH}$ receives competitive funding from the Australian Research Council, with Linkage funding from Mitsubishi Heavy Industries and AkzoNobel. DAS receives competitive research funding from the National Health and Medical Research Council, Medical Research Future Fund, Australia and New Zealand College of Anaesthetists Foundation and the Alzheimer's Association. All other authors declare no competing interests.

Ethical approval Institutional Review Board approval was obtained in accordance with state and federal guidelines (Ref: LRR 099/20, ID: 64592). Informed consent was obtained from all participants.

\section{References}

1. Schwartz J, King CC, Yen MY (2020) Protecting health care workers during the COVID-19 coronavirus outbreak - lessons from Taiwan's SARS response. Clin Infect Dis. https://doi. org/10.1093/cid/ciaa255

2. Cohen E (2020) Disease detectives hunting down more information about "super spreader" of Wuhan coronavirus. CNN Health 
3. Patel ZM, Fernandez-Miranda J, Hwang PH et al (2020) Precautions for endoscopic transnasal skull base surgery during the COVID-19 pandemic. Neurosurgery 87(1):66-67

4. Margo J (2020) Extreme viral risk cuts ear, nose and throat surgery. Australian Financial Review

5. Mitchell RA, King JAJ, Goldschlager T, Wang YY (2020) Impact of COVID-19 on pituitary surgery. ANZ J Surg 90(6):963-964

6. Zhu W, Huang X, Zhao H, Jiang X (2020) A COVID-19 patient who underwent endonasal endoscopic pituitary adenoma resection: a case report. Neurosurgery 87(2):E140-E146

7. Chan DYC, Chan DTM, Mak WK, Wong GKC, Poon WS (2020) Letter: rongeurs, neurosurgeons, and COVID-19: how do we protect health care personnel during neurosurgical operations in the midst of aerosol-generation from high-speed drills? Neurosurgery 87(2):E164-E165

8. Patel ZM, Fernandez-Miranda J, Hwang PH et al (2020) In reply: precautions for endoscopic transnasal skull base surgery during the COVID-19 pandemic. Neurosurgery. 87(2):E162-E163

9. Kolias A, Tysome J, Donnelly N et al (2020) A safe approach to surgery for pituitary and skull base lesions during the COVID-19 pandemic. Acta Neurochir (Wien) 162(7):1509-1511

10. Jenkins A (2020) Letter: transmission of COVID-19 during neurosurgical procedures-some thoughts. Neurosurgery 87(1):E68

11. Germanò A, Raffa G, Angileri FF, Cardali SM, Tomasello F (2020) Coronavirus disease 2019 (COVID-19) and neurosurgery: literature and neurosurgical societies recommendations update. World Neurosurg 139:e812-e817

12. Sharma D, Rubel KE, Ye MJ et al (2020) Cadaveric simulation of endoscopic endonasal procedures: analysis of droplet splatter patterns during the COVID-19 pandemic. Otolaryngol-Head Neck Surg 163(1):145-150

13. Workman AD, Xiao R, Feng A et al (2020) Suction mitigation of airborne particulate generated during sinonasal drilling and cautery [published online Jun 18, 2020]. Int Forum Allergy Rhinol. https://doi.org/10.1002/alr.22644

14. Workman AD, Welling DB, Carter BS et al (2020) Endonasal instrumentation and aerosolization risk in the era of COVID-19: simulation, literature review, and proposed mitigation strategies. Int Forum Allergy Rhinol 10(7):798-805

15. Dharmarajan H, Freiser ME, Sim E et al (2020) Droplet and aerosol generation with endonasal surgery: methods to mitigate risk during the COVID-19 pandemic [published online Aug 11, 2020]. Otolaryngol - Head Neck Surg. https://doi.org/10.1177/01945 99820949802

16. Dharan S, Pittet D (2002) Environmental controls in operating theatres. J Hosp Infect 51(2):79-84

17. Hambraeus A (1988) Aerobiology in the operating room: a review. J Hosp Infect 11:68-76

18. Yan J, Grantham M, Pantelic J et al (2018) Infectious virus in exhaled breath of symptomatic seasonal influenza cases from a college community. Proc Natl Acad Sci U S A 115(5):1081-1086

19. Mittal R, Ni R, Seo JH (2020) The flow physics of COVID-19. J Fluid Mech 894:1-14

20. Tellier R, Li Y, Cowling BJ, Tang JW (2019) Recognition of aerosol transmission of infectious agents: a commentary. BMC Infect Dis 19(1):1-9

21. Bourouiba L (2020) Turbulent gas clouds and respiratory pathogen emissions: potential implications for reducing transmission of COVID-19. J Am Med Assoc 323(18):1837-1838

22. Workman AD, Jafari A, Welling DB et al (2020) Airborne aerosol generation during endonasal procedures in the era of COVID19: risks and recommendations. Otolaryngol - Head Neck Surg 163(3):465-470

23. Sattar SA, Ijaz MK (1987) Spread of viral infections by aerosols. Crit Rev Environ Control 17(2):89-131

24. Ong SWX, Tan YK, Chia PY et al (2020) Air, surface environmental, and personal protective equipment contamination by severe acute respiratory syndrome coronavirus 2 (SARSCoV-2) from a symptomatic patient. JAMA - J Am Med Assoc 323(16):1610-1612

25. Correia G, Rodrigues L, Gameiro da Silva M, Gonçalves T (2020) Airborne route and bad use of ventilation systems as non-negligible factors in SARS-CoV-2 transmission. Med Hypotheses 141:109781

Publisher's Note Springer Nature remains neutral with regard to jurisdictional claims in published maps and institutional affiliations. 